\title{
Boiled coffee consumption and the risk of prostate cancer: follow-up of 224,234 Norwegian men 20-69 years
}

\author{
A Tverdal ${ }^{\star 1}$ \\ ${ }^{1}$ Department of Pharmacoepidemiology, Norwegian Institute of Public Health, PO Box 4404 Nydalen, Oslo NO-0403, Norway
}

Background: There is insufficient epidemiological evidence on the relationship between type of coffee and the risk of prostate cancer.

Methods: The risk of prostate cancer by use of boiled vs not boiled coffee were assessed in a prospective study of 224,234 men 20-69 years. 5740 incident prostate cancers were identified.

Results: With no coffee as reference group the hazard ratios of $<1-4,5-8$ and $9+$ cups per day of boiled coffee only were $0.84(0.73-0.96), 0.80(0.70-0.92)$ and $0.66(0.55-0.80), P$-trend $=0.00$. The corresponding figures for not boiled coffee were 0.89 (0.80-0.99), $0.91(0.81-1.02)$ and $0.86(0.74-1.00)$, $P$-trend $=0.22$.

Conclusion: An inverse relationship between number of cups per day and the risk of prostate cancer was present only for the boiled coffee type.

The strength of evidence regarding the relationship between coffee consumption and prostate cancer is graded as 'limited-no conclusion' (World Cancer Research Fund/American Institute for Cancer Research, 2007). Since this report was published studies have produced results varying from no association (Nilsson et al, 2010; Bosire et al, 2013; Geybels et al, 2013) to inverse association for overall prostate cancer (Li et al, 2013), high-grade and lethal (Wilson et al, 2011, 2013; ), aggressive (Shafique et al, 2012) or localised type (Discacciati et al, 2013). The Nilsson paper studied the intake of boiled $v s$ filtered coffee in relation to several cancer types with no result for prostate cancer. Meta-analyses have concluded with no harmful effect of coffee (Park et al, 2010), an inverse relationship (Yu et al, 2011; Cao et al, 2013; Lu et al, 2014; Zhong et al, 2014), and inverse relationship for fatal prostate cancer (Discacciati et al, 2014). The studies have focused on number of cups per day. Two diterpenes cafestol and kahweol have demonstrated anti-carcinogenic activity (Cavin et al, 2002). A paper filter traps most of these substances (Harvard Health Letter, 2012). Boiled coffee that is not filtered has been used by a substantial part of Norwegians (Stensvold et al, 1989). I studied the coffee-prostate cancer relationship with emphasis on the boiled $v s$ the not boiled type.

\section{MATERIALS AND METHODS}

The Norwegian cardiovascular screening programme was proceeding from 1974 to 1999. In 1985 the questions on coffee consumption were introduced. All men 40-42 years were invited and samples aged 20-39 and 43-69. The attendance rate was around $80 \%$ in the 1980 s decreasing to $60 \%$ in 1999 . Altogether 228,041 men attended the screenings. Of these 3322 did not give sufficient information on the coffee variables or the potential confounders that we adjusted for and 485 had been diagnosed with prostate cancer prior to the screening. This left 224,234 men without prostate cancer and with complete information on all the confounders, for analysis. The same procedures have been used throughout the study period. Detailed description is given in Bjartveit et al (1979) and Stensvold et al (1989). 
The participants answered a questionnaire which was sent together with the invitation letter. At the screening site the questionnaire was checked for inconsistencies and height, weight and blood pressure were measured. A blood sample was drawn and serum was analysed for total cholesterol and triglycerides. From 1985 to 1994 the questions on coffee read: (i) 'How many cups of coffee do you usually drink a day?' with preset categories 0 or $<1$ cup, 1-4, 5-8 and $9+$ cups per day, (ii) 'What type of coffee do you usually drink daily?' with categories boiled, filtered, instant, decaffeinated and do not drink coffee. More than one type of coffee could be ticked. In 1994 the questions were changed to: (i) 'How many cups of boiled coffee do you drink daily?', (ii) 'How many cups of other types of coffee do you drink daily'. Both questions could be answered. Four types of coffee were defined: none, not boiled, boiled and not boiled, and boiled coffee only. I categorised number of cups into the categories none, $<1$ to 4 (denoted $<1-4$ ), 5-8 and $9+$ cups per day. In the period from 1985 to 1994, where I have detailed information on type of coffee, $83 \%$ of the not boiled group drank filtered coffee only. The participants answered questions on smoking habits, diabetes history and physical activity during leisure time.

I calculated person-years from time of examination until date of a cancer diagnosis, emigration or death, whichever came first, or 31 December 2010. I estimated the adjusted hazard ratios by the Cox proportional hazards model. Both type of coffee and cups per day were entered as dummy variables with no coffee as the reference group. Three sets of adjustments were done: (i) for age, (ii) for age and cups per day and (iii) for age, cups per day, smoking (yes, no), total cholesterol, triglycerides, systolic blood pressure (SBP), body mass index (BMI), height, physical active (yes, no), diabetes (yes, no) and year of screening. Cups per day was entered as 1, 2, 3, 4 when testing for trend. One of the four categories could be ticked for physical activity: $1=$ sedentary and $2-4=$ intensive. Categories 2-4 were defined as physically active. Total cholesterol, triglycerides, SBP, BMI, height and year of screening were entered as continuous variables. Geographical differences were taken into consideration by introducing county as shared frailty in the Cox model.

For 27,583 men I have compatible information on coffee intake registered on average 3 years earlier. The agreement (kappa) was 0.72 .

Information on cancer incidence and cause of death was taken from the Norwegian Cancer Registry and the Cause of Death Registry. The death and emigration date came from the National Person Registry. The linkage to these registries was possible because of the personal identification number attributed to all citizens in Norway.

The Norwegian Cancer Registry codes according to ICD-7. Cancer prostate is code 177 . We found 5740 new cases of prostate cancer and 622 prostate cancer deaths during follow-up. The basis for the diagnoses of the cases was histologic examination in $96 \%$ of the cases. Prostate specific antigen (PSA) was the basis for only 32 cases $(0.6 \%)$.

\section{RESULTS}

Baseline information by type of coffee is given in Table 1 . The distribution was $8 \%$ no coffee, $62 \%$ not boiled, $9 \%$ both boiled and not boiled, and $21 \%$ boiled coffee only.

The crude incidence was somewhat higher in the boiled only group (Table 2). Adjustment for age reversed the ranking with the lowest hazard ratio in the boiled only group. Additional adjustment for cups per day lifted the hazard ratios a bit closer to 1.0. Further adjustment for several potential confounders did not influence the hazard ratios. In addition, adjustments for county did not substantially alter the hazard ratios, neither did an additional introduction of a quadratic term of age. Removal of the first 3 years of follow up did not influence the hazard ratio estimates (data not shown).

Men who drank 9 or more cups per day had the lowest risk of prostate cancer with drinkers of $<1-4$ and 5-8 cups per day in between (Table 3). Stratification by coffee type gave a more pronounced dose-response relationship in the boiled only group. A trend test was significant among the users of boiled only, but not among users of not boiled coffee.

Information on metastasis was available for 4340 cases. An association similar to that in Table 2 was found for localised cases. No significant associations were found for 728 regional and 424 distant cases.

\section{DISCUSSION}

In this follow-up study there was a lower risk of prostate cancer among drinkers of boiled coffee than drinkers of other types of coffee.

Several potentially chemo-preventive effects of coffee have been discussed in the literature. Among these are: (i) the content of

Table 1. Baseline characteristics for 224,234 men aged 20-69 years

\begin{tabular}{|c|c|c|c|c|}
\hline Type of coffee & No coffee & Not boiled & Boiled and not boiled & Boiled only \\
\hline$N$ & 17432 & 139764 & 20105 & 46933 \\
\hline Age (years) & 41.8 & 42.6 & 42.1 & 43.8 \\
\hline cups per day ${ }^{a}$ & 0 & 1.70 & 1.84 & 1.82 \\
\hline Total cholesterol $\left(\mathrm{mmoll}^{-1}\right)$ & 5.59 & 5.86 & 5.98 & 6.17 \\
\hline Triglycerides $\left(\mathrm{mmoll}^{-1}\right)$ & 2.23 & 2.11 & 2.17 & 2.24 \\
\hline Systolic blood pressure $(\mathrm{mm} \mathrm{Hg})$ & 132.7 & 134.8 & 134.4 & 136.2 \\
\hline BMI $\left(\mathrm{kg} \mathrm{m}^{-2}\right)$ & 25.9 & 25.7 & 25.7 & 25.7 \\
\hline Height $(\mathrm{cm})$ & 178.9 & 178.8 & 178.5 & 177.3 \\
\hline Year of examination & 1993 & 1992 & 1991 & 1991 \\
\hline Smoker (\%) & 17.7 & 41.0 & 41.4 & 48.7 \\
\hline Physically active ${ }^{\mathbf{b}}(\%)$ & 83.4 & 83.0 & 83.7 & 82.6 \\
\hline Diabetes (\%) & 1.02 & 1.04 & 0.81 & 1.19 \\
\hline
\end{tabular}


Table 2. Hazard ratios (HR) with $95 \%$ confidence interval $(95 \% \mathrm{Cl})$ of prostate cancer, by type of coffee

\begin{tabular}{|c|c|c|c|c|}
\hline Type of coffee & No coffee & Not boiled & Boiled and not boiled & Boiled only \\
\hline Cases, $n$ & 389 & 3503 & 500 & 1348 \\
\hline$P$-years & 293299 & 2442386 & 363212 & 844751 \\
\hline Per 100000 & 133 & 143 & 138 & 160 \\
\hline HR $(95 \% \mathrm{Cl})$, age adjusted & Reference group & $0.88(0.80-0.98)$ & $0.88(0.77-1.00)$ & $0.76(0.68-0.86)$ \\
\hline HR $(95 \% \mathrm{Cl})$, age and cups adjusted & Reference group & $0.94(0.84-1.07)$ & $0.94(0.81-1.10)$ & $0.82(0.72-0.94)$ \\
\hline HR $(95 \% \mathrm{Cl})$, multivariate adjusted ${ }^{a}$ & Reference group & $0.94(0.83-1.06)$ & $0.94(0.81-1.09)$ & $0.82(0.72-0.94)$ \\
\hline
\end{tabular}

Table 3. Hazard ratios (HR) with $95 \%$ confidence interval $(95 \% \mathrm{Cl})$ of prostate cancer, by type of coffee and cups per day.

\begin{tabular}{|c|c|c|c|c|c|c|}
\hline All types of coffee & None & $<1-4$ cups per day & 5-8 cups per day & $9+$ cups per day & $P$-trend & $P$-trend ${ }^{\mathrm{a}}$ \\
\hline $\begin{array}{l}\text { Cases, } n \\
P \text {-years }\end{array}$ & $\begin{array}{c}389 \\
293299\end{array}$ & $\begin{array}{c}2404 \\
1519301\end{array}$ & $\begin{array}{c}2305 \\
1578576\end{array}$ & $\begin{array}{c}642 \\
552473\end{array}$ & & \\
\hline HR $(95 \% \mathrm{Cl})$, age adjusted & Reference group & $0.87(0.78-0.97)$ & $0.87(0.78-0.97)$ & $0.76(0.67-0.86)$ & 0.00 & 0.02 \\
\hline HR $(95 \% \mathrm{Cl})$, multivariate adjusted ${ }^{\mathbf{b}}$ & Reference group & $0.88(0.79-0.98)$ & $0.88(0.79-0.98)$ & $0.78(0.69-0.89)$ & 0.00 & 0.08 \\
\hline \multicolumn{7}{|l|}{ Not boiled coffee } \\
\hline Cases & 389 & 1669 & 1467 & 367 & & \\
\hline$P$-years & 293299 & 1073441 & 1044360 & 324584 & & \\
\hline HR (95\% Cl) age adjusted & Reference group & $0.88(0.79-0.99)$ & $0.89(0.80-1.00)$ & $0.83(0.72-0.96)$ & 0.06 & 0.50 \\
\hline HR $(95 \% \mathrm{Cl})$, multivariate adjusted ${ }^{\mathbf{b}}$ & Reference group & $0.89(0.80-0.99)$ & $0.91(0.81-1.02)$ & $0.86(0.74-1.00)$ & 0.22 & 0.90 \\
\hline \multicolumn{7}{|l|}{ Boiled and not boiled } \\
\hline Cases & 389 & 176 & 248 & 76 & & \\
\hline$P$-years & 293299 & 126431 & 171089 & 65692 & & \\
\hline HR (95\% Cl) age adjusted & Reference group & $0.84(0.70-1.00)$ & $0.93(0.79-1.09)$ & $0.81(0.64-1.04)$ & 0.11 & 0.93 \\
\hline HR (95\% Cl), multivariate adjusted ${ }^{\mathbf{b}}$ & Reference group & $0.83(0.69-0.99)$ & $0.88(0.75-1.04)$ & $0.74(0.57-0.96)$ & 0.02 & 0.58 \\
\hline \multicolumn{7}{|l|}{ Boiled coffee only } \\
\hline Cases & 389 & 559 & 590 & 199 & & \\
\hline$P$-years & 293299 & 319429 & 363126 & 162196 & & \\
\hline HR (95\% Cl) age adjusted & Reference group & $0.83(0.73-0.95)$ & $0.80(0.70-0.91)$ & $0.65(0.55-0.78)$ & 0.00 & 0.01 \\
\hline HR $(95 \% \mathrm{Cl})$, multivariate adjusted ${ }^{\mathbf{b}}$ & Reference group & $0.84(0.73-0.96)$ & $0.80(0.70-0.92)$ & $0.66(0.55-0.80)$ & 0.00 & 0.02 \\
\hline
\end{tabular}

antioxidants (chlorogenic acid), (ii) the association with lower insulin levels through a possible pathway of higher adiponectin levels and (iii) two specific diterpines, cafestol and kahweol (Yu et al, 2011; Cao et al, 2013; Lu et al, 2014; Zhong et al, 2014). Cafestol and kahweol show biological effects that support the hypothesis of anti-carcinogenic effect (Cavin et al, 2002). These two diterpines are largely retained in a paper filter (Harvard Health Letter, 2012). As $83 \%$ of the not boiled group drank filtered coffee only, the comparison between boiled and not boiled coffee is largely a comparison between coffee with and without cafestol and kahweol.

Cafestol and kahweol have been shown to have total cholesterol raising effects (Urgert et al, 1995). The multivariate analysis showed no relation between total cholesterol and the risk of prostate cancer (data not shown). Thus the pathway of a potential favourable effect of cafestol and kahweol on prostate cancer risk is likely not through the effect on lipids.

The diverging findings in different studies might be owing to the different brewing methods. Most studies have used number of cups per day as exposure without taking the type of coffee into account. Urgert et al, (1995) found that cafestol and kahweol from coffee grounds raised serum cholesterol and alanine transferase activity similar to cafestol and kahweol from boiled coffee or coffee oil (Weusten-Van der Wouw et al, 1994). The particle content from coffee grounds varied across the unfiltered types but also among the other types of coffee. The lowest content was found in the paper filtered types with particle content close to zero. Thus the distribution of use of coffee types in a population might influence the relationship between coffee consumption and the risk of prostate cancer.

There has been a switch away from the boiled type during follow-up. The prevalence of the use of boiled type, with or without the use of other types as well, was $25 \%$ in the first half of the study period and $16 \%$ in the second half. This change in use of coffee type has likely pushed the hazard ratio estimates towards 1.0.

The introduction of PSA testing has probably influenced the distribution of subtypes of prostate cancer in the direction of more non-advanced types. However, only an insignificant fraction of the cases were diagnosed based on the PSA testing.

The follow-up in our study is complete with information on cancer, death and emigration taken from national registers. Almost all cases were verified by histological examination.

The limitations of the study include self-reported information on coffee at only one occasion. Furthermore information on risk factors such as family history and tomato use (lycopenes) is not recorded.

This study does support the hypothesis of a lower risk of prostate cancer for heavy drinkers of boiled coffee.

\section{ACKNOWLEDGEMENTS}

The study has been approved by the Regional Committees for Medical and Health Research, and the Norwegian Data Protection Authority has given licence to establish the data set. Since 1973 I have been with the National Health Screening Service that conduct 
the cardiovascular surveys in Norway. In 2002 the institution became a part of the Norwegian Institute of Public Health. I have established the data set, done the analyses and written the manuscript.

\section{CONFLICT OF INTEREST}

I had full access to all the data in the study and take responsibility for integrity of the data and the accuracy of data analysis. The author declares no conflict of interest.

\section{REFERENCES}

Bjartveit K, Foss OP, Gjervig T, Lund-Larsen PG (1979) The cardiovascular disease study in Norwegian counties. Background and organization. Acta Med Scand Suppl 634: 1-70.

Bosire C, Stampfer MJ, Subar AF, Wilson KM, Park Y, Sinha R (2013) Coffee consumption and the risk of overall and fatal prostate cancer in the NIH-AARP Diet and Health Study. Cancer Causes Control 24: $1527-1534$.

Cao S, Liu L, Yin X, Wang Y, Liu J, Lu Z (2013) Coffee consumption and risk of prostate cancer: a meta-analysis of prospective cohort studies. Carcinogenesis 35: 256-261.

Cavin C, Holzhaeuser D, Scharf G, Constable A, Huber WW, Schilter B (2002) Cafestol and kahweol, two coffee specific diterpines with anticarcinogenic activity. Food Chem Toxicol 40: 1155-1163.

Discacciati A, Orsini N, Andersson S-O, Andrén O, Johansson J-E, Mantzoros CS, Wolk A (2013) Coffee consumption and risk of localized, advanced and fatal prostate cancer: a population-based prospective study. Ann Oncol 24: 1912-1918.

Discacciati A, Orsini N, Wolk A (2014) Coffee consumption and risk of nonaggressive, aggressive and fatal prostate cancer-a-dose-response meta-analysis. Ann Oncol 25: 584-591.

Geybels MS, Neuhouser ML, Stanford JL (2013) Associations of tea and coffee with prostate cancer risk. Cancer Causes Control 24: 941-948.

Harvard Health Letter (2012) http://www.health.harvard.edu/newsletters/ Harvard_Health_Letter/2012/January/what-is-it-about-coffee (accessed 4 November 2014).
Li Q, Kakizaki M, Sugawara Y, Tomata Y, Watanabe T, Nishino Y, Tsuji I (2013) Coffee consumption and the risk of prostate cancer: the Ohsaki Cohort study. Brit J Cancer 108: 2381-2389.

Lu Y, Zhai L, Zeng J, Peng Q, Wang J, Deng Y, Xie L, Mo C, Yang S, Li S, Qin X (2014) Coffee consumption and prostate cancer risk: an updated meta-analysis. Cancer Causes Control 25: 591-604.

Nilsson LM, Johansson I, Lenner P, Lindahl B, Guelpen BV (2010) Consumption of filtered and boiled coffee and the risk of incident cancer: a prospective cohort study. Cancer Causes Control 21: 1533-1544.

Park C-H, Myung S-K, Kim T-Y, Seo HG, Jeon Y-J, Kim Y. Korean Meta-Analysis (KORMA) Study Group (2010) Coffee consumption and risk of prostate cancer: a meta-analysis of epidemiological studies. BJUI International 106: 762-769.

Shafique K, McLoone P, Qureshi K, Leung H, Hart C, Morrison DS (2012) Coffee consumption and prostate cancer risk: further evidence for inverse relationship. Nutr J 11: 42.

Stensvold I, Tverdal A, Foss OP (1989) The effect of coffee on blood lipids and blood pressure. Results from a Norwegian cross-sectional study, men and women, 40-42 years. J Clin Epidemiol 42: 877-884.

Urgert R, Schulz AGM, Katan MB (1995) Effects of cafestol and kahweol from coffee grounds on serum lipids and serum liver enzymes in humans. Am J Clin Nutr 61: 149-154.

Weusten-Van der Wouw MPME, Katan MB, Viani R, Huggett AC, Liardon R, Lund-Larsen PG, Thelle DS, Ahola I, Aro A, Meyboom S, Beynen AC (1994) Identity of the cholesterol-raising factor from boiled coffee and its effects on liver function enzymes. J Lipid Res 35: 721-733.

Wilson KM, Kasperzyk JL, Rider JR, Kenfield S, van Dam RM, Stampfer MJ, Giovannucci E, Mucci LA (2011) Coffee consumption and prostate cancer risk and progression in the Health Professionals Follow-up Study. J Natl Cancer Inst 103: 1-9.

Wilson KM, Bälter K, Möller E, Adami H-O, Andrén O, Andersson S-O, Grönberg H, Mucci LA (2013) Coffee and risk of prostate cancer incidence and mortality in the Cancer of the Prostate in Sweden Study. Cancer Causes Control 24: 1575-1581.

World Cancer Research Fund/American Institute for Cancer Research (2007) Food, Nutrition, Physical Activity and the Prevention of Cancer: a Global Perspective. pp 305. AICR: Washington, DC.

Yu X, Bao Z, Zou J, Dong J (2011) Coffee consumption and risk of cancers: a meta-analysis of cohort studies. BMC Cancer 11: 96.

Zhong S, Chen W, Yu X, Chen Z, Hu Q, Zhao J (2014) Coffee consumption and risk of prostate cancer: an up-to-date meta-analysis. Eur J Clin Nutr 68: $330-337$. 